\title{
Telephone-based behavioral activation with mental imagery for depression: A pilot randomized clinical trial in isolated older adults during the Covid-19 pandemic
}

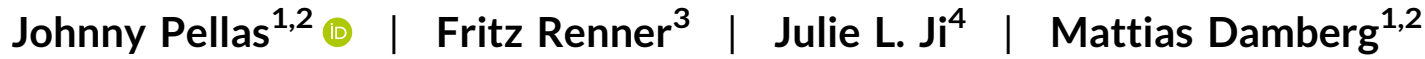

${ }^{1}$ Department of Public Health and Caring Sciences, Uppsala University, Uppsala, Sweden

${ }^{2}$ Centre for Clinical Research, Uppsala University, Västmanland County Hospital, Västerås, Sweden

${ }^{3}$ Department of Clinical Psychology and Psychotherapy, University of Freiburg, Breisgau, Germany

${ }^{4}$ School of Psychological Science, University of Western Australia, Perth, Western Australia, Australia

\section{Correspondence}

Johnny Pellas, Centrum för Klinisk Forskning, Västmanlands sjukhus, 72189 Västerås, Sweden.

Email: Johnny.pellas@regionvastmanland.se

Funding information

Landstinget Västmanland; Uppsala University

\begin{abstract}
Objectives: To shield vulnerable persons, particularly the elderly, during the Covid-19 pandemic governments around the world have advised to use social distancing and self-isolation. Social isolation might put older adults at an increased risk for mental health problems such as depression. There is a need for brief, easy-accessible psychological treatments for depressive symptoms that can be delivered remotely. The aim of this study was to investigate the feasibility, acceptability, and preliminary efficacy of telephone-delivered Behavioral Activation with Mental Imagery (BA-MI) for the treatment of depressive symptoms in individuals 65 years and older living in isolation during the Covid19 pandemic.

Methods: In this open-label pilot randomized clinical trial, $N=41$ individuals aged 65 years or older with clinically significant symptoms of depression were randomly assigned to either a BA-MI treatment condition, or an Attention-Assessment control condition delivered over the telephone over a 4-week period.

Results: Depressive symptoms decreased more in the treatment condition compared to the control condition. At post-treatment, 2 out of 16 participants in the treatment condition met diagnostic criteria for depression compared to 9 out of 13 in the control condition. Most participants in the treatment condition were satisfied with the treatment and few adverse effects were observed.

Conclusions: This pilot study suggests that behavioral activation with mental imagery delivered over the telephone is feasible, acceptable, and potentially efficacious for the treatment of depressive symptoms in older individuals living in isolation. Replication in larger samples is needed.
\end{abstract}

\section{KEYWORDS}

activity scheduling, behavioral activation, depression, mental imagery, older adults, social isolation

This is an open access article under the terms of the Creative Commons Attribution License, which permits use, distribution and reproduction in any medium, provided the original work is properly cited.

(c) 2021 The Authors. International Journal of Geriatric Psychiatry published by John Wiley \& Sons Ltd. 


\section{Key points}

- The Covid-19 pandemic has exacerbated the need for brief, accessible psychological treatments for depressive symptoms that can be remotely delivered to isolated older adults.

- This pilot RCT investigated the feasibility and preliminary efficacy of telephone-based Behavioral Activation with Mental Imagery (BA-MI) for depression in this sample.

- BA-MI led to a greater decrease in depressive symptoms and increases in behavioral activation in the treatment group compared to the control group.

- BA-MI may help to alleviate depressive symptoms in isolated older adults.

\section{1 | INTRODUCTION}

The Severe Acute Respiratory Syndrome Coronavirus 2 (SARS-CoV-2) causing the Coronavirus disease 2019 (Covid-19) became a pandemic in the year 2020 and into 2021. Covid-19-related mortality rates were the highest in older adults particularly those aged 70 years and above. In Sweden, between April and October 2020, the government urged people 70 years and older to limit physical contact with other people and to stay at home as much as possible, a strategy called social distancing. ${ }^{1}$ While these measures are important to shield vulnerable individuals, mental health experts have raised serious concerns over deteriorating mental health during and after the pandemic, ${ }^{2}$ particularly among older adults. ${ }^{3}$ Indeed, social isolation is related to an increase risk for depression and anxiety disorders among older adults. ${ }^{4}$ Thus there is a need to develop and evaluate scalable psychological interventions for mental health problems for this patient group.

Evidence from previous epidemics and the current pandemic indicates that there is an urgent need for effective remotely delivered psychological interventions aimed at improving mental health among older individuals. ${ }^{5}$ Research on the SARS epidemic in 2000 indicates that quarantine and isolation may lead to an increase in mental health conditions, such as depression. ${ }^{6}$ Depression in older adults increases the risk of mortality and morbidity, ${ }^{7}$ reduces quality of life, ${ }^{8}$ and leads to functional impairments. ${ }^{9}$ A study from Hong Kong during SARS found a nearly $32 \%$ increase in suicide rates among older individuals. ${ }^{10} \mathrm{~A}$ recent review showed that social distancing has a negative impact on the mental as well as physical health of older individuals, including increased levels of depression, anxiety, and sleep problems. ${ }^{5}$ A recent study in older adults from Sweden found that half of the sample reported staying at home all of the time, and that $44.4 \%$ of females and $25.7 \%$ of males reported feeling depressed. ${ }^{11}$

Current evidence-based treatments for depression in older adults include antidepressant medication, ${ }^{12}$ psychological in terventions such as Cognitive-Behavioral Therapy (CBT), ${ }^{13}$ and physical activity. ${ }^{14}$ Previous studies have shown that the majority of older adults prefer psychological treatments to medication, ${ }^{15}$ which poses a challenge during the Covid-19 pandemic as such treatments are often delivered face to face. Psychological treatments delivered via the Internet are as efficacious as face to face, ${ }^{16}$ but only $3 \%-4 \%$ of the individuals 65 years and above in Sweden use digital applications instead of physical healthcare visits. ${ }^{17}$ CBT has been shown to work when delivered via the telephone ${ }^{18}$ and has proven to be feasible for older adults, ${ }^{19}$ and one study showed that it may even result in lower attrition compared to face-to-face psychotherapy. ${ }^{20}$ Due to the wide availability and accessibility of telephones, telephone-based psychological treatment could be an optimal intervention for older adults, particularly during pandemics.

Behavioral Activation (BA) is a brief psychological treatment that aims to (1) increase engagement in adaptive activities, (2) decrease engagement in activities that maintain depression or increase risk for depression, and (3) solve problems that limit access to rewarding activities or that maintain aversive control. ${ }^{21}$ Common BA strategies are self-monitoring of activities and mood, planning and scheduling of activities in line with the patients' needs and goals, and problem solving. ${ }^{21,22}$ BA is effective in reducing depressive symptoms ${ }^{23,24}$ and there is emerging evidence suggesting that BA is also an effective intervention for older adults. ${ }^{25}$ BA can be delivered in a brief format, ${ }^{26,27}$ and has been shown to be feasible for older individuals in as few as four sessions. ${ }^{28,29}$ However, depression is often characterized by low motivation and a lack of energy, which might make it more difficult for patients to initiate engagement in scheduled activities thereby reducing the efficacy of BA interventions. Thus identifying interventions that directly target these motivational difficulties could provide an additional route to promote greater behavioral engagement in scheduled reward activities. One way to facilitate motivation for planned activities might be via prospective mental imagery.

Mental imagery refers to the representation and experience of sensory information without external input. ${ }^{30,31}$ By drawing upon prior knowledge and experiences, mental imagery can amplify the anticipation of reward-related emotions. ${ }^{32,33}$ Anticipation of the pleasant and rewarding consequences of future behavior, in turn, predicts reward motivation and reward-motivated behavior. ${ }^{34-36}$ Indeed, it has been shown that simulating engagement in scheduled pleasant and rewarding activities via mental imagery can increase motivation to engage in these activities. ${ }^{37-39}$ Similar mental imagery interventions have successfully been used by older individuals. ${ }^{40}$

The aim of this open-label pilot randomized clinical trial was to investigate the feasibility and preliminary efficacy of a brief telephone-delivered BA intervention, focused on activity scheduling augmented with mental imagery, for the treatment of 
depressive symptoms in individuals 65 years and older in isolation during the Covid-19-pandemic. We hypothesized that participants randomized to the active treatment condition would show a stronger decrease in depressive symptoms (primary outcome) and improve more on secondary outcomes, compared to participants randomized to an attention-assessment control condition.

\section{METHODS}

\section{1 | Design}

The present study was an open-label pilot randomized clinical trial ( $N=41$ ) with two conditions: (1) telephone-delivered Behavioral Activation with Mental Imagery (BA-MI), and (2) AttentionAssessment Control with weekly follow-up calls. This was a single-site trial, with all participants recruited from one county in Sweden and treated through the Adult Psychiatric Clinic at Västmanland County Hospital. The study received ethical approval by the Swedish Ethical Review Authority (2020-02079) and all participants provided written informed consent. The study was preregistered with ClinicalTrials.gov (NCT04508868). Note that the initial pre-registered plan was to conduct a full-scale trial, but due to changes in self-isolation restrictions for older individuals in Sweden from 22 October 2020, the recruitment had to be terminated early.

\section{2 | Participants}

Participants were approached using advertisements in local newspapers that invited individuals aged 65 years or older living in the county of Västmanland to participate in a telephone-based treatment of depressive symptoms. The inclusion criteria were (1) reporting clinically significant depressive symptoms as defined by scores above 12 on the Montgomery-Åsberg Depression Rating Selfrating Scale (MADRS-S), and/or scores above 9 on the Patient Health Questionnaire 9-item (PHQ-9), and/or scores above 5 on the Geriatric Depression Rating Scale 15-item-short form (GDS-15), and/or via structured clinical interviews; (2) access to telephone; (3) fluent in written and spoken Swedish; (4) residing in the County of Västmanland; and (5) willing to participate in the trial. Exclusion criteria included severe depression defined by clinical diagnosis, elevated risk of suicide, current substance use disorder, current or previous manic/hypomanic episodes, current psychotic disorder, current diagnosis of dementia/major neurocognitive disorder, currently receiving psychological therapy, or currently undergoing pharmacological treatments that commenced less than 1 month ago. Participant characteristics are described in Table 1. Baseline ratings on primary and secondary outcome measures are described in Table 3.
TABLE 1 Baseline demographic and clinical characteristics

\begin{tabular}{|c|c|c|}
\hline Baseline characteristic & $\begin{array}{l}\text { Treatment group } \\
(N=20)\end{array}$ & $\begin{array}{l}\text { Control group } \\
(\mathrm{N}=20)\end{array}$ \\
\hline Age, mean (SD) & 75.95 (8.16) & $75.15(6.20)$ \\
\hline Women, $n$ (\%) & $16(80)$ & $17(85)$ \\
\hline Partner/cohabiting, n (\%) & $9(45)$ & $7(35)$ \\
\hline \multicolumn{3}{|l|}{ Psychotropic medication } \\
\hline $\begin{array}{l}\text { Antidepressant } \\
\text { medication, } n \text { (\%) }\end{array}$ & $0(0)$ & $5(25)$ \\
\hline $\begin{array}{l}\text { Anxiolytic medication, } n \\
\text { (\%) }\end{array}$ & $2(10)$ & $2(10)$ \\
\hline Sleep medication, $n$ (\%) & $5(25)$ & $3(15)$ \\
\hline
\end{tabular}

Psychiatric diagnoses according to $\mathrm{MINI}^{\mathrm{a}}$

$\begin{array}{lcc}\text { Major depression } & 16(80) & 14(70) \\ \text { Panic disorder } & 1(5) & 0(0) \\ \begin{array}{l}\text { Posttraumatic stress } \\ \text { disorder }\end{array} & 2(10) & 0(0) \\ \begin{array}{l}\text { Generalized anxiety } \\ \quad \text { disorder }\end{array} & 0(0) & 1(5)\end{array}$

Abbreviations: MINI, Mini International Neuropsychiatric Interview 7.0; SD, Standard deviation

${ }^{a}$ No current diagnoses of bipolar disorder, psychotic syndromes, or alcohol-/substance use disorder since these were exclusion criteria.

\section{3 | Materials}

\subsection{1 $\mathrm{MINI}$}

The Mini International Neuropsychiatric Interview 7.0 (MINI), ${ }^{41}$ a structured clinical interview, was used to assess the presence/ absence of common psychiatric disorders at enrollment as well as assessing the presence/absence of depression post-treatment.

\subsection{2 | Primary outcome measure}

\section{MADRS-S}

The primary outcome measure was the MADRS-S, which is a nineitem questionnaire, used to measure severity of depression the past 2 weeks. ${ }^{42}$ The score ranges from 0 to 54 , with higher scores indicating higher depression severity.

\subsection{3 | Secondary outcome measures}

\section{GDS-15}

Depressive symptoms were also measured using the GDS-15. ${ }^{43}$ The GDS-15 is a 15-item questionnaire used to identify depression in older individuals with scores ranging from 0-15. 
TABLE 2 Session components in the treatment group

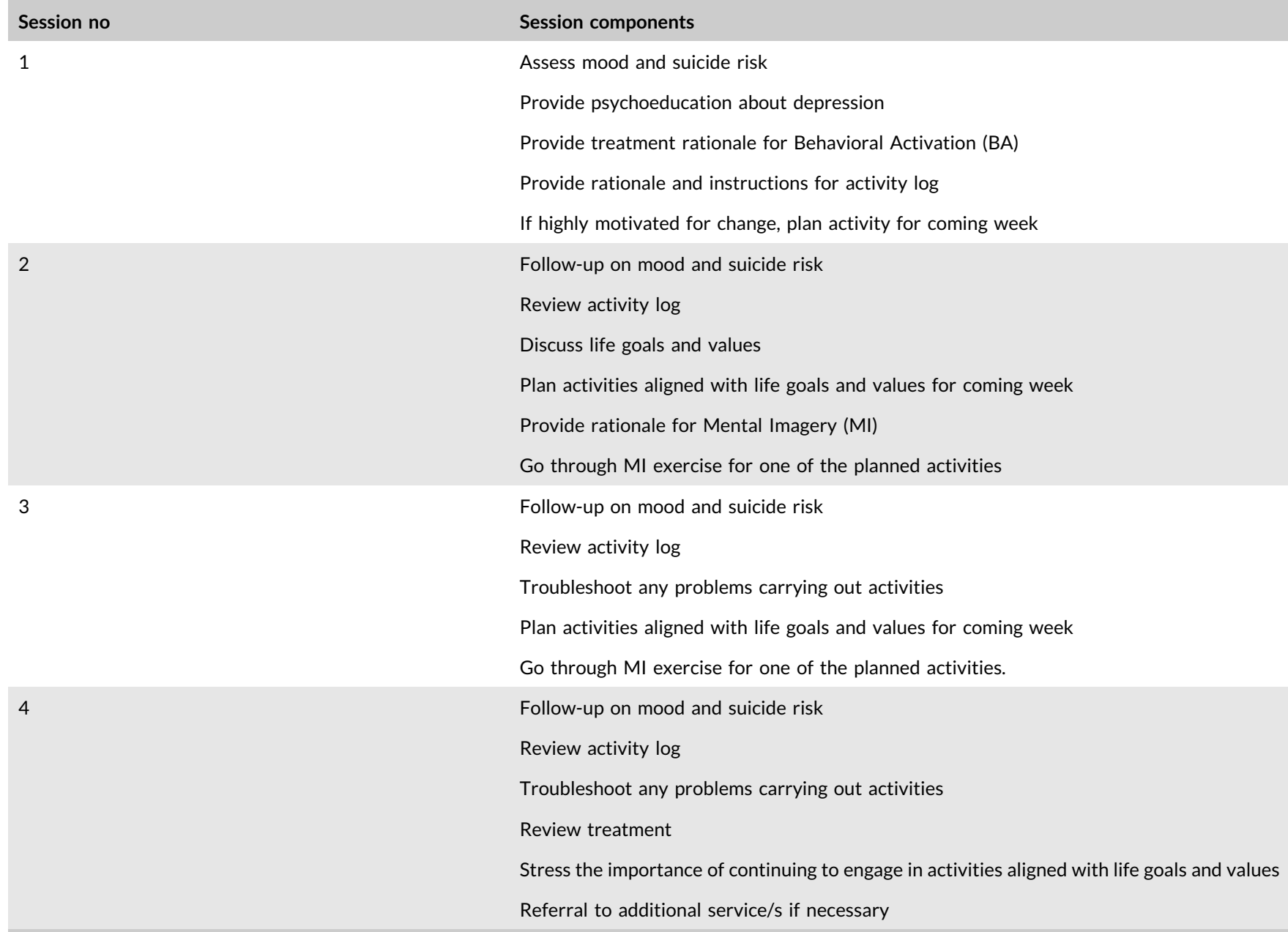

TABLE 3 Means (M), standard deviations (SD) and effect sizes of primary and secondary outcome measures at baseline and postintervention

\begin{tabular}{|c|c|c|c|c|c|c|c|c|c|c|c|c|c|}
\hline & \multicolumn{6}{|c|}{ Treatment group $(N=20)$} & \multicolumn{6}{|c|}{ Control group $(N=18)$} & \multirow{3}{*}{ Effect size (g) } \\
\hline & \multicolumn{3}{|c|}{ Baseline } & \multicolumn{3}{|c|}{ Post-intervention } & \multicolumn{3}{|c|}{ Baseline } & \multicolumn{3}{|c|}{ Post-intervention } & \\
\hline & $M$ & SD & $n$ & $M$ & SD & $n$ & M & SD & $n$ & $M$ & SD & $n$ & \\
\hline \multicolumn{14}{|l|}{ Primary outcome } \\
\hline MADRS-S & 17.30 & 6.88 & 20 & 12.45 & 7.21 & 20 & 18.20 & 5.36 & 20 & 19.33 & 8.96 & 18 & 0.85 \\
\hline PHQ-9 & 9.65 & 5.06 & 20 & 6.95 & 5.49 & 19 & 9.75 & 5.59 & 20 & 10.72 & 7.51 & 18 & 0.58 \\
\hline GAD-7 & 7.05 & 5.04 & 20 & 5.30 & 5.17 & 20 & 7.60 & 4.24 & 20 & 8.50 & 4.94 & 18 & 0.63 \\
\hline BADS-SF & 22.10 & 6.59 & 20 & 33.40 & 10.02 & 20 & 21.90 & 6.16 & 20 & 23.67 & 7.81 & 18 & 1.08 \\
\hline
\end{tabular}

Abbreviations: BADS-SF, Behavioral Activation for Depression Scale - Short Form; GAD-7, Generalized Anxiety Disorder 7-item; GDS-15, Geriatric Depression Rating Scale 15-item short form; MADRS-S, Montgomery-Åsberg Depression Rating Self-rating Scale; PHQ-9, Patient Health Questionnaire 9; Psi-Q, Plymouth Sensory Imagery Questionnaire; WHODAS-12, WHO Disability Assessment Schedule 12-item. 


\section{PHQ-9}

The PHQ-9 is a nine-item questionnaire used to identify depression as well as measuring severity of depression with scores ranging from 0 to 27 , with higher scores indicating higher depression severity. ${ }^{44}$

\section{GAD-7}

Anxiety symptoms were assessed with the GAD-7, a seven-item questionnaire used to identify generalized anxiety disorder as well as measuring severity of anxiety symptoms. ${ }^{45}$ The score ranges from 0 to 21 , with higher scores indicating higher anxiety severity.

\section{BADS-SF}

Changes in avoidance and activation was measured using the Behavioral Activation for Depression Scale-Short Form (BADSSF). ${ }^{46}$

\section{WHODAS-12}

Functional impairment was assessed with the WHODAS-12, a selfrating scale with 12 items. ${ }^{47}$

\subsection{4 | Mental imagery ability}

\section{Psi-Q}

Mental imagery was assessed at baseline and post-intervention using the Plymouth Sensory Imagery Questionnaire (Psi-Q), ${ }^{48}$ translated by Johanna M. Hoppe and Emily Holmes. Psi-Q is a 35 -item questionnaire assessing the vividness of mental imagery. In this study, we used the visual subscale with five items, with a total score ranging from 0 to 50 , with higher scores indicating higher imagery ability.

\subsection{5 | latrogenic effects}

NEQ

Adverse effects were measured using the Negative Effects Scale (NEQ)-short form, a 20-item questionnaire used to assess adverse and unwanted effects of psychological treatments. ${ }^{49}$ In the analysis, only the items rated by the participant as probably caused by the treatment were included. Adverse effects were also monitored by the therapists throughout the interventions.

\subsubsection{Feasibility and acceptability}

Feasibility was assessed by recording recruitment and dropout rates. Time was measured for each session, in the treatment group as well as in the control group. Acceptability was measured with the question "overall, how satisfied were you with the treatment you received?", with ratings ranging from 1 to 5 representing "very dissatisfied" to "very satisfied", with 3 representing a neutral alternative, "neither satisfied nor dissatisfied".

\subsection{Interventions}

The treatment manual as well as the manual for the control group was adapted into web-based versions on the system Entermedic. The digital manuals enabled us to upload the correct session manuals for each participant, digitalize in-session ratings, as well as providing a checklist for each treatment component to ensure therapists adherence to the manuals, inspired by Serfaty and colleagues. $^{50}$

\subsection{1 | Treatment group}

A treatment manual was constructed, based on two interventions: a four-session brief BA treatment for primary care (BA-PC) published by Funderburk and colleagues, ${ }^{28}$ with the addition of a mental imagery script by Renner and colleagues' ${ }^{\prime 37}$ sessions two and three. The interventions and patient materials were translated into Swedish by the corresponding author, and was then reviewed by two senior clinical psychologists and a primary care physician. The BA-PC was adapted to comply with government restrictions due to Covid-19. The session outline is described in Table 2.

\subsection{2 | Control group}

The control group was placed on a waiting list with weekly follow-up calls. The manual for the control group included follow-up on the patient's psychological symptoms, assessment of suicide risk and answering practical questions about the study. The therapists were instructed to be supportive by using validation techniques for thoughts and feelings, but not to engage in behavioral interventions such as activity planning or problem solving.

\subsection{3 | Therapists}

Five psychologists participated in the study, of which two were senior licensed psychologists and three were psychologists during their 1year clinical internship before license. All of the psychologists had at least basic training in cognitive behavioral therapy. They had a 1day training workshop which included information about and practical training in delivering the treatment manual. The therapists had a supervision session with the corresponding author every 2 weeks to resolve practical issues and troubleshoot difficult treatment situations.

\section{5 | Procedure}

Interested participants contacted the research unit and received information about the study. A psychologist or research nurse screened the participants concerning age, subjective symptoms of 
depression, county of residence, and language comprehension. Participants who met the screening criteria were sent detailed information about the study, informed consent forms, and baseline questionnaires. Upon return of signed consent forms and baseline questionnaires, the corresponding author phoned the participant and conducted a clinical interview including a structured psychiatric interview to evaluate eligibility. Participants who met all inclusion criteria and no exclusion criteria were consecutively randomized to either treatment or control, with one weekly call for four weeks. After 4 weeks, the control group also were offered the treatment. The participants completed depression ratings after each call week 1-3, and at week 4 (posttreatment/post-control) they completed a more comprehensive questionnaire.

\subsection{1 | Randomization and blinding}

An independent statistician generated a 1:1, 6-block randomization sequence. The statistician prepared sequentially numbered opaque envelopes to conceal allocation until the moment of randomization. The corresponding author was responsible for evaluating eligibility and enrolling subjects in the study groups. The baseline questionnaires were scored by a research nurse and blinded to the psychologist until after the structured clinical interview. All subsequent selfratings were performed by the participants at home and sent by mail, and were scored by a research nurse and thereby blinded to the psychologists. A structured clinical interview was performed at week 4/post-treatment by the patient's therapist.

\subsection{Measures}

The MADRS-S was assessed weekly. Acceptability and adverse effects were assessed at post-treatment. All other measures were assessed at baseline and post-treatment.

\subsection{1 | Analysis plan}

To test the effect of the intervention condition on the primary outcome measure, a repeated-measures ANOVA was conducted with condition (BA-MI vs. control) as the between subject factor and time (baseline vs. post-intervention) as the within subject factor. Betweengroups effect sizes post-treatment on the primary outcome measure and continuous secondary outcome measures were calculated using Hedge's $g$. Hedge's $g$ was chosen as it's more suitable for smaller samples as well as differences in sample size between groups. The magnitude of the effect sizes is interpreted as follows: in line with the recommendation for gerontological research ${ }^{51}$ : $0.15=$ small, $0.40=$ medium, and $0.75=$ large. Difference in the number of participants meeting diagnostic criteria for depression post-treatment was calculated using Fisher's exact test.

\section{3 | RESULTS}

Recruitment took place between August and October 2020. Fortyone participants were randomized to the intervention $(N=20)$ or the control condition $(N=21)$. Participant flow is described in the CONSORT diagram in Figure 1.

\section{1 | Feasibility and acceptability}

Of 65 screened individuals, 41 (63\%) were found eligible for the study and subsequently randomized. Of the 41 randomized participants, 2 dropped out and 1 was excluded during the trial, all in the control group, making the overall dropout rate $7.3 \%$.

Mean time per session in the treatment group was $43.55-\mathrm{min}$ session 1, 43.35-min session 2, 32.10-min session 3, and 29.05min session 4. Time per session in the control group was 16.06min session 1, 12.61-min session 2, 12.89-min session 3, and 16.67-min session 4. All participants received the treatment or control condition in line with the manual.

Eighteen out of 20 participants in the treatment group rated treatment satisfaction. Five rated themselves as very satisfied with the treatment, seven as somewhat satisfied, five as neither satisfied nor dissatisfied, none as somewhat dissatisfied, and one as very dissatisfied with the treatment.

\section{2 | Primary outcome measure}

The means and $95 \%$ confidence interval for each group on MADRS-S across the different time points are shown in Figure 2.

In the repeated-measures ANOVA, Mauchly's test indicated that the assumption of sphericity had been violated $\left(x^{2}[9]=37.44\right.$, $p=<0.001)$; therefore, degrees of freedom were corrected using Greenhouse-Geisser estimates of sphericity $(\varepsilon=0.58)$. The results of the repeated-measures ANOVA revealed that there was a significant Condition $\times$ Time interaction for the primary outcome measure $\left(F[2.30,73.64]=3.71, p=0.024, \eta^{2}=0.10\right)$, indicating a stronger decrease in depressive symptoms in the treatment group compared to the control group.

Means, standard deviations, and between-group effect size posttreatment on the primary outcome measure are shown in Table 3.

\section{3 | Secondary outcome measures}

Means, standard deviations, and effect sizes of secondary outcome measures at baseline and post-intervention are presented in Table 3. Post-intervention, 2 out of 16 participants in the treatment group still met depression criteria according to the MINI, which is lower than the control group, where 9 out of 13 participants still met criteria, but not statistically significant according to Fisher's exact test (two-tail) $p=0.073$. 
Excluded $(n=21)$

- Declined to participate/did not consent $(n=14)$

-Trial enrollment terminated $(n=5)$

- Did not meet inclusion criteria $(n=2)$

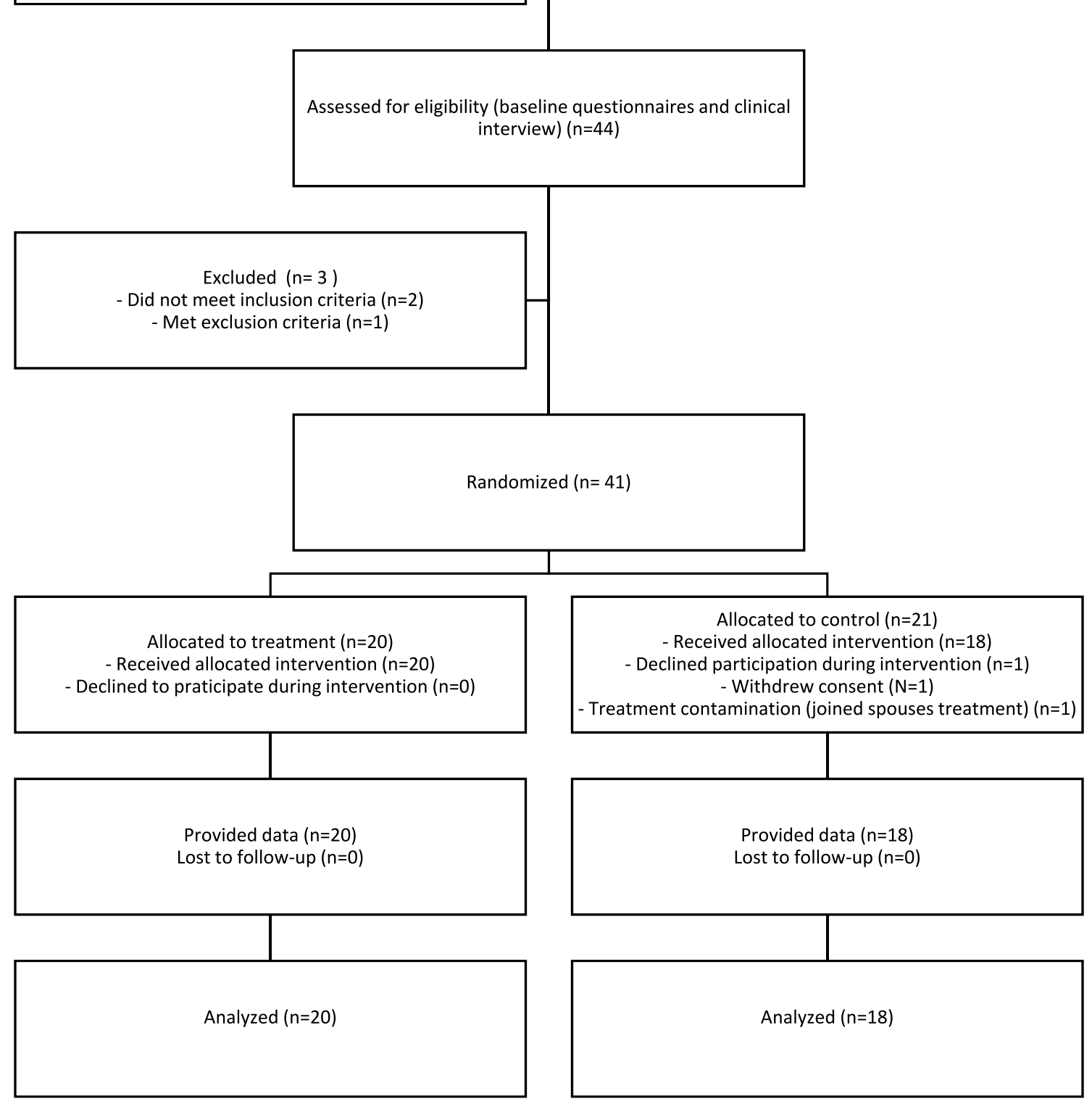

FIGURE 1 Participant flow through the trial

\section{4 | latrogenic effects}

Nineteen participants in the treatment group completed the NEQ and 4 (21\%) reported adverse effects that they attributed to the treatment. The most frequent adverse effects were increased anxiety, more unpleasant feelings, that unpleasant memories resurfaced, that they didn't always understand their treatments, that the treatment didn't produce positive results, and that became afraid that other people would find out about their ongoing treatment. No serious adverse effects or serious deterioration was reported by the therapists during the interventions. 


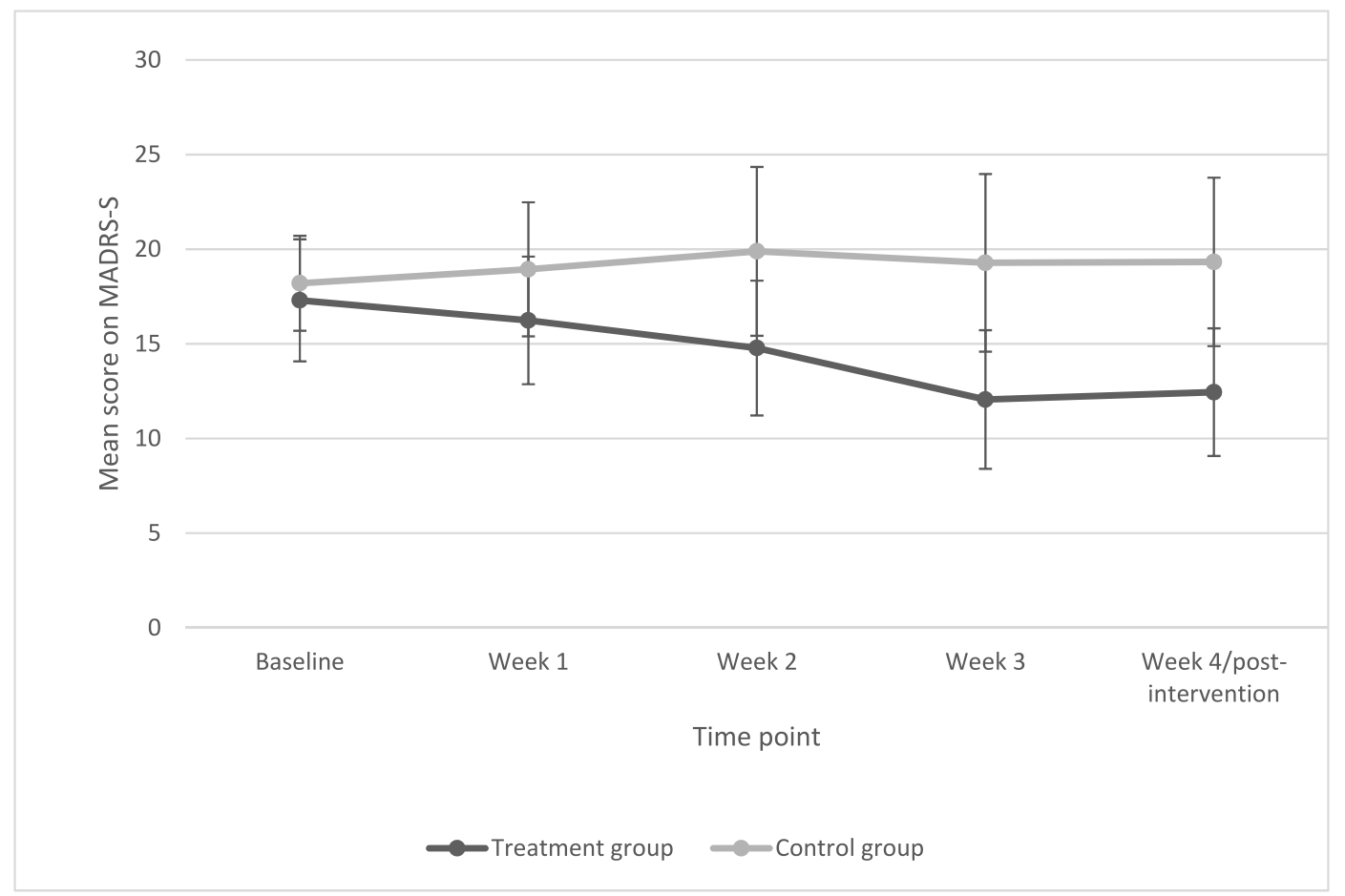

FIGURE 2 Mean depression severity over the different time points. Error bars are $95 \%$ confidence intervals. MADRS-S, MontgomeryÅsberg Depression Rating Self-rating Scale

\section{DISCUSSION}

This pilot study is, to our knowledge, the first to test the feasibility and preliminary efficacy of telephone-based BA-MI aimed at reducing depressive symptoms in older adults during a pandemic. The treatment and study design were found to be feasible, and results indicated that a 4-week BA-MI intervention reduced depression symptoms (MADRS-S) and increased behavioral activation (BADS-SF) relative to an attention-assessment control condition.

BA treatment aims to increase engagement in rewarding everyday activites via activity scheduling. ${ }^{52}$ Numerous randomized controlled trials ${ }^{53-55}$ and meta analyses ${ }^{23,24}$ have shown the efficacy of BA. The evidence of BA for older adults is limited. The findings of our pilot study are in line with previous research indicating that BA might be an effective intervention for older adults, ${ }^{25}$ and shows promise in as few as four sessions as previously demonstrated. ${ }^{28}$ In addition to these previous findings, we could show that BA can be delivered remotely over the telephone and thereby reach individuals in isolation. This is crucial given that, independent of the pandemic situation, older individuals might not have access to online therapy resources.

The results of this study support the idea that mental imagery simulations of daily activities could be used to facilitate BA treatment for depression. In this study, a behavioral activation with mental imagery intervention led to a stronger increase in behavioral activation compared to an attention control condition. This is in line with previous research demonstrating a positive impact of mental imagery on behavioral activation in individuals with depression. ${ }^{38}$ Given the emotion amplifying properties of mental imagery, it has been argued that mental imagery might have motivational properties that facilitate engagement in planned activities. However, previous studies have not specifically combined BA procedures (activity scheduling) with mental imagery practice in a clinical sample. While our results support this idea, it should be noted that given the lack of a BA control condition without mental imagery, we cannot draw any conclusions about the added value of mental imagery in this study.

In general, the results of this study should be interpreted with caution, given the small sample size that may lead to inflated effect sizes. $^{56}$ The number of individuals fulfilling depression criteria according to MINI decreased from 16 to 2 in the treatment group, and from 13 to 9 in the control group, which is promising given the brevity of the intervention.

Although the majority of participants $(67 \%)$ in the treatment group reported being "very satisfied" or "somewhat satisfied" with the treatment, five participants reported being "neither satisfied nor dissatisfied", and one was "very dissatisfied" with the treatment. Four participants reported adverse effects on the NEQ that they attributed to the treatment, which include experiences of anxiety, unpleasant memories, that they didn't always understand their treatment, lack of positive results, and that concerns about stigma if other people would find out about their treatment. However, no serious adverse effects or serious deterioration in symptoms was observed by the therapists during the interventions. Future studies should focus on understanding individual differences in the acceptability of telephone-based BA treatment with mental imagery in this population. Further, many participants found the NEQ scale difficult 
to perform, and it would be of interest to further test the validity of this scale in a population of older adults.

Since this treatment is designed to be an accessible first-line treatment, the inclusion criteria were broad and resulted in a heterogeneous sample ranging from subclinical depressive symptoms to moderate depressive disorder. Baseline characteristics showed that the randomization produced fairly equal groups, with the exception of ongoing antidepressant treatment, which only occurred in the control group, although there was a higher frequency of depression diagnoses in the treatment group. All patients receiving medication were on stable doses, but it is possible that this affected the results. We note that although the majority of the present study's participants $(80 \%$ in the BA-MI group, $70 \%$ in the Control group) met criteria for major depression, they were recruited from the community rather than through clinics. Thus, further research is required to evaluate the feasibility and effectiveness of the BA-MI intervention in more severe clinical populations and those recruited via routine clinical practice.

The findings of this study, if replicated, have potential implications for the treatment of depression in older individuals in isolation. Brief telephone-based behavioral activation could potentially be used to support older individuals to increase engagement in adaptive activities with positive effects on mood. These effects might further be facilitated by the motivation enhancing properties of mental imagery. Our findings from this initial study need replication in larger sample and future studies should include a behavioral activation without mental imagery control condition to determine the added value of mental imagery. It will be particularly pertinent for future research to evaluate the added impact of mental imagery on mood, behavior, as well as treatment acceptance. Future research should also investigate additional factors that may enhance the effectiveness of remotely delivered $\mathrm{BA}-\mathrm{MI}$ interventions. One such factor may be the addition of live face-to-face interaction via video link delivery. Although we are not aware of studies that have assessed the impact of adding video-link to telephone-based interventions, it is possible that both voice and face-to-face interaction with the therapist, via video link, may deliver added benefits compared to telephone voice interaction alone. However, it is also possible that video link may not be more effective than telephone delivery in older adult populations living in isolation due to technological and skills barriers.

Limitations of this study include (1) time per session differed between the treatment group and control groups. Since this was a new combination of intervention manuals, it was difficult to predict time consumption, and therefore a minimal attention-assessment control was used. Second, the trial was open labeled, which might have influenced the results, for example, by making participants in the control group frustrated when waiting to start their treatment. However, in light of the pandemic, we thought it would be unethical not to disclose this to the participants or to use a sham condition. Third, when recommendations regarding self-isolation restrictions changed, half of the participants were ongoing in the trial. This might have influenced the results, but since participants were included and randomized consecutively, both groups were equally influenced. Fourth, the MINI- interviews were conducted by the patients' therapists, which may have contributed to bias; however, the ratings were blinded to the therapists and researchers. Finally, this paper only reports the results post treatment. Future studies are needed to investigate long-term effects.

To summarize, the Covid-19 pandemic has highlighted the need for brief, easy-accessible psychological treatments for depressive symptoms that can be delivered by remote, particularly for older individuals. The investigated BA-MI treatment seems feasible, acceptable, and potentially efficacious for the treatment of depressive symptoms in older individuals in isolation during the Covid-19 pandemic. Further studies with larger samples are needed to replicate these findings.

\section{ACKNOWLEDGMENTS}

We wish to thank psychologists Gunilla Schiölde, Tobias Thornell, Ida-Maria Jonsson, and Elin Byström for your contributions as therapists; research nurses Marie Stenius-Svensson and Angelica Norling for practical assistance as well as GCP-expertise Lotta Nilsson and Mariana Ehn for digitalizing the treatment manuals; Tony Wiklund for the help with randomization; Dr Simon Liljeström för aiding in the statistical analyses; Dr Marie Kanstrup for support in the initial phase of the study as well as for comments on the treatment manual; Dr Jennifer Funderburk for generously sharing the BA-PC treatment manual and patient materials. This study was funded by a Covid-19 research grant from the County of Västmanland. Open Access funding provided by Uppsala University.

\section{CONFLICT OF INTERESTS}

The authors declare no conflicts of interest.

\section{DATA AVAILABILITY STATEMENT}

The data that support the findings of this study are available from the corresponding author upon reasonable request.

\section{ORCID}

Johnny Pellas (D) https://orcid.org/0000-0002-0707-0832

\section{REFERENCES}

1. Du som är 70 år eller äldre (om Covid-19). Folkhälsomyndigheten; 2020. http://www.folkhalsomyndigheten.se/publicerat-material/ publikationsarkiv/d/du-som-ar-70-ar-eller-aldre/

2. Holmes EA, O'Connor RC, Perry VH, et al. Multidisciplinary research priorities for the COVID-19 pandemic: a call for action for mental health science. Lancet Psychiatry. 2020;7(6):547-560. https://doi.org/ 10.1016/S2215-0366(20)30168-1

3. Skoog I. COVID-19 and mental health among older people in Sweden. Int Psychogeriatr. 2020;32:1-1175. https://doi.org/10.1017/ S104161022000143X

4. Santini ZI, Jose PE, York Cornwell E, et al. Social disconnectedness, perceived isolation, and symptoms of depression and anxiety among older Americans (NSHAP): a longitudinal mediation analysis. Lancet Publ Health. 2020;5(1):e62-e70. https://doi.org/10.1016/S24682667(19)30230-0

5. Sepúlveda-Loyola W, Rodríguez-Sánchez I, Pérez-Rodríguez P, et al. Impact of social isolation due to COVID-19 on health in older people: mental and physical effects and recommendations. J Nutr Health Aging. 2020:1-10. https://doi.org/10.1007/s12603-020-1469-2 
6. Hawryluck L, Gold WL, Robinson S, Pogorski S, Galea S, Styra R. SARS control and psychological effects of quarantine, Toronto, Canada. Emerg Infect Dis. 2004;10(7):1206-1212. https://doi.org/10. 3201/eid1007.030703

7. Schulz R, Beach SR, Ives DG, Martire LM, Ariyo AA, Kop WJ. Association between depression and mortality in older adults: the Cardiovascular Health Study. Arch Intern Med. 2000;160(12): 1761-1768.

8. Pyne JM, Patterson TL, Kaplan RM, Gillin JC, Koch WL, Grant I. Assessment of the quality of life of patients with major depression. Psychiatr Serv. 1997;48(2):224-230. https://doi.org/10.1176/ps.48. 2.224

9. Stuck AE, Walthert JM, Nikolaus T, Bula CJ, Hohmann C, Beck JC. Risk factors for functional status decline in community-living elderly people: a systematic literature review. Soc Sci Med. 1999;48(4): 445-469.

10. Yip PS, Cheung YT, Chau PH, Law YW. The impact of epidemic outbreak: the case of severe acute respiratory syndrome (SARS) and suicide among older adults in Hong Kong. Crisis. 2010;31(2):86-92. https://doi.org/10.1027/0227-5910/a000015

11. Gustavsson J, Beckman L. Compliance to recommendations and mental health consequences among elderly in Sweden during the initial phase of the COVID-19 pandemic - a cross sectional online survey. Int J Environ Res Publ Health. 2020;17(15):5380. https://doi. org/10.3390/ijerph17155380

12. Thorlund K, Druyts E, Wu P, Balijepalli C, Keohane D, Mills E. Comparative efficacy and safety of selective serotonin reuptake inhibitors and serotonin-norepinephrine reuptake inhibitors in older adults: a network meta-analysis. J Am Geriatr Soc. 2015;63(5): 1002-1009. https://doi.org/10.1111/jgs.13395

13. Huang AX, Delucchi K, Dunn LB, Nelson JC. A systematic review and meta-analysis of psychotherapy for late-life depression. Am J Geriatr Psychiatr. 2015;23(3):261-273. https://doi.org/10.1016/j.jagp.2014. 04.003

14. Catalan-Matamoros D, Gomez-Conesa A, Stubbs B, Vancampfort D. Exercise improves depressive symptoms in older adults: an umbrella review of systematic reviews and meta-analyses. Psychiatry Res. 2016;244:202-209. https://doi.org/10.1016/j.psychres.2016. 07.028

15. Gum AM, Areán PA, Hunkeler E, et al. Depression treatment preferences in older primary care patients. Gerontologist. 2006;46(1): 14-22. https://doi.org/10.1093/geront/46.1.14

16. Andrews $G$, Basu A, Cuijpers $P$, et al. Computer therapy for the anxiety and depression disorders is effective, acceptable and practical health care: an updated meta-analysis. J Anxiety Disord. 2018;55:70-78. https://doi.org/10.1016/j.janxdis.2018.01.001

17. Andersson J. Svenskarna och Internet 2019: Undersökning om svenskarnas Internetvanor. Internetstiftelsen; 2019. https://svenskarnao chinternet.se/app/uploads/2019/10/svenskarna-och-internet-2019a4.pdf

18. Tutty S, Spangler DL, Poppleton LE, Ludman EJ, Simon GE. Evaluating the effectiveness of cognitive-behavioral teletherapy in depressed adults. Behav Ther. 2010;41(2):229-236. https://doi.org/ 10.1016/j.beth.2009.03.002

19. Barrera TL, Cummings JP, Armento $M$, et al. Telephone-delivered cognitive-behavioral therapy for older, rural veterans with depression and anxiety in home-based primary care. Clin Gerontol. 2017;40(2):114-123. https://doi.org/10.1080/07317115.2016. 1254133

20. Mohr DC, Ho J, Duffecy J, et al. Effect of telephone-administered vs face-to-face cognitive behavioral therapy on adherence to therapy and depression outcomes among primary care patients: a randomized trial. J Am Med Assoc. 2012;307(21):2278-2285. https://doi.org/ 10.1001/jama.2012.5588
21. Dimidjian S, Barrera JM, Martell C, Muñoz RF, Lewinsohn PM. The origins and current status of behavioral activation treatments for depression. Annu Rev Clin Psychol. 2011;7(1):1-38. https://doi.org/10. 1146/annurev-clinpsy-032210-104535

22. Kanter JW, Manos RC, Bowe WM, Baruch DE, Busch AM, Rusch LC. What is behavioral activation? A review of the empirical literature. Clin Psychol Rev. 2010;30(6):608-620. https://doi.org/10.1016/j.cpr. 2010.04.001

23. Ekers D, Richards D, Gilbody S. A meta-analysis of randomized trials of behavioural treatment of depression. Psychol Med. 2008;38(5): 611-623. https://doi.org/10.1017/s0033291707001614

24. Cuijpers P, van Straten A, Warmerdam L. Behavioral activation treatments of depression: a meta-analysis. Clin Psychol Rev. 2007; 27(3):318-326. https://doi.org/10.1016/j.cpr.2006.11.001

25. Orgeta $\mathrm{V}$, Brede J, Livingston G. Behavioural activation for depression in older people: systematic review and meta-analysis. $\mathrm{Br} J$ Psychiatry. 2017;211(5):274-279. https://doi.org/10.1192/bjp.bp. 117.205021

26. Lejuez CW, Hopko DR, LePage JP, Hopko SD, McNeil DW. A brief behavioral activation treatment for depression. Cogn Behav Pract. 2001;8(2):164-175. https://doi.org/10.1016/s1077-7229(01)8 0022-5

27. Lejuez CW, Hopko DR, Acierno R, Daughters SB, Pagoto SL. Ten year revision of the brief behavioral activation treatment for depression: revised treatment manual. Behav Modif. 2011;35(2): 111-161. https://doi.org/10.1177/0145445510390929

28. Funderburk JS, Pigeon WR, Shepardson RL, Maisto SA. Brief behavioral activation intervention for depressive symptoms: patient satisfaction, acceptability, engagement, and treatment response. Psychol Serv. 2019. https://doi.org/10.1037/ser0000328

29. Funderburk JS, Pigeon WR, Shepardson RL, et al. Treating depressive symptoms among veterans in primary care: a multi-site RCT of brief behavioral activation. J Affect Disord. 2021;283:11-19. https:// doi.org/10.1016/j.jad.2021.01.033

30. Kosslyn SM, Ganis G, Thompson WL. Neural foundations of imagery. Nat Rev Neurosci. 2001;2(9):635-642. https://doi.org/10.1038/ 35090055

31. Pearson J, Naselaris T, Holmes EA, Kosslyn SM. Mental imagery: functional mechanisms and clinical applications. Trends Cogn Sci. 2015;19(10):590-602. https://doi.org/10.1016/j.tics.2015.08.003

32. Moulton ST, Kosslyn SM. Imagining predictions: mental imagery as mental emulation. Philos Trans $R$ Soc Lond B Biol Sci. 2009; 364(1521):1273-1280. https://doi.org/10.1098/rstb.2008.0314

33. Schacter DL, Addis DR, Buckner RL. Episodic simulation of future events: concepts, data, and applications. Ann N Y Acad Sci. 2008;1124:39-60. https://doi.org/10.1196/annals.1440.001

34. Hallford DJ, Sharma MK. Anticipatory pleasure for future experiences in schizophrenia spectrum disorders and major depression: a systematic review and meta-analysis. Br J Clin Psychol. 2019;58(4): 357-383. https://doi.org/10.1111/bjc.12218

35. Mellers BA, McGraw AP. Anticipated emotions as guides to choice. Curr Dir Psychol Sci. 2001;10(6):210-214. https://doi.org/10.1111/ 1467-8721.00151

36. Sherdell L, Waugh CE, Gotlib IH. Anticipatory pleasure predicts motivation for reward in major depression. J Abnorm Psychol. 2012;121(1):51-60. https://doi.org/10.1037/a0024945

37. Renner F, Murphy FC, Ji JL, Manly T, Holmes EA. Mental imagery as a "motivational amplifier" to promote activities. Behav Res Ther. 2019;114:51-59. https://doi.org/10.1016/j.brat.2019.02.002

38. Renner F, Ji JL, Pictet A, Holmes EA, Blackwell SE. Effects of engaging in repeated mental imagery of future positive events on behavioural activation in individuals with major depressive disorder. Cogn Ther Res. 2017;41(3):369-380. https://doi.org/10.1007/ s10608-016-9776-y 
39. Ji JL, Geiles D, Saulsman LM. Mental imagery-based episodic simulation amplifies motivation and behavioural engagement in planned reward activities. Behav Res Ther. 2021;145:103947. https://doi.org/ 10.1016/j.brat.2021.103947

40. Murphy SE, Clare O'Donoghue M, Drazich EH, Blackwell SE, Chris tina Nobre A, Holmes EA. Imagining a brighter future: the effect of positive imagery training on mood, prospective mental imagery and emotional bias in older adults. Psychiatry Res. 2015;230(1):36-43. https://doi.org/10.1016/j.psychres.2015.07.059

41. Sheehan DV, Lecrubier Y, Sheehan KH, et al. The Mini-International Neuropsychiatric Interview (M.I.N.I.): the development and validation of a structured diagnostic psychiatric interview for DSM-IV and ICD-10. J Clin Psychiatry. 1998;59(Suppl 20):22-33. quiz 34-57.

42. Svanborg $P$, Asberg M. A new self-rating scale for depression and anxiety states based on the Comprehensive Psychopathological Rating Scale. Acta Psychiatr Scand. 1994;89(1):21-28. https://doi.org/ 10.1111/j.1600-0447.1994.tb01480.x

43. Sheikh JI, Yesavage JA. (1986). Geriatric Depression Scale (GDS): Recent Evidence and Development of a Shorter Version. Clin Gerontol, 5(1-2), 165-173. https://doi.org/10.1300/J018v05n01_09.

44. Kroenke K, Spitzer RL, Williams JB. The PHQ-9: validity of a brief depression severity measure. J Gen Intern Med. 2001;16(9):606-613. https://doi.org/10.1046/j.1525-1497.2001.016009606.x

45. Spitzer RL, Kroenke K, Williams JB, Lowe B. A brief measure for assessing generalized anxiety disorder: the GAD-7. Arch Intern Med. 2006;166(10):1092-1097. https://doi.org/10.1001/archinte.166. 10.1092

46. Manos RC, Kanter JW, Luo W. The behavioral activation for depression scale-short form: development and validation. Behav Ther. 2011;42(4):726-739. https://doi.org/10.1016/j.beth.2011. 04.004

47. Mätning av hälsa och funktionshinder : Manual till WHO:s formulär för bedömning av funktionshinder WHO Disability Assessment Schedule WHODAS 2.0. Socialstyrelsen; 2015. https://www.socialstyrelsen.se/ globalassets/sharepoint-dokument/artikelkatalog/ovrigt/2015-5-1. pdf

48. Andrade J, May J, Deeprose C, Baugh S-J, Ganis G. Assessing vividness of mental imagery: the Plymouth sensory imagery questionnaire. Br J Psychol. 2014;105(4):547-563. https://doi.org/10. 1111/bjop.12050
49. Rozental A, Kottorp A, Forsstrom D, et al. The Negative Effects Questionnaire: psychometric properties of an instrument for assessing negative effects in psychological treatments. Behav Cogn Psychother. 2019;47(5):559-572. https://doi.org/10.1017/s135246 5819000018

50. Serfaty M, Shafran R, Vickerstaff V, Aspden T. A pragmatic approach to measuring adherence in treatment delivery in psychotherapy. Cogn Behav Ther. 2020;49:1-360. https://doi.org/10.1080/16506 073.2020.1717594

51. Brydges CR. Effect size guidelines, sample size calculations, and statistical power in gerontology. Innov Aging. 2019;3(4):igz036. https://doi.org/10.1093/geroni/igz036

52. Behavioral activation for Depression: A Clinician's Guide. Guilford Press; 2010.

53. Dimidjian S, Hollon SD, Dobson KS, et al. Randomized trial of behavioral activation, cognitive therapy, and antidepressant medication in the acute treatment of adults with major depression. J Consult Clin Psychol. 2006;74(4):658-670. https://doi.org/10.1037/ 0022-006x.74.4.658

54. Richards DA, Ekers D, McMillan D, et al. Cost and outcome of Behavioural Activation versus Cognitive Behavioural Therapy for Depression (COBRA): a randomised, controlled, non-inferiority trial. Lancet. 2016;388(10047):871-880. https://doi.org/10.1016/S01406736(16)31140-0

55. Moradveisi L, Huibers MJ, Renner F, Arasteh M, Arntz A. Behavioural activation v. antidepressant medication for treating depression in Iran: randomised trial. Br J Psychiatry. 2013;202(3):204-211. https://doi.org/10.1192/bjp.bp.112.113696

56. Button KS, loannidis JPA, Mokrysz C, et al. Power failure: why small sample size undermines the reliability of neuroscience. Nat Rev Neurosci. 2013;14(5):365-376. https://doi.org/10.1038/nrn3475

How to cite this article: Pellas J, Renner F, Ji JL, Damberg M. Telephone-based behavioral activation with mental imagery for depression: A pilot randomized clinical trial in isolated older adults during the Covid-19 pandemic. Int J Geriatr Psychiatry. 2021;1-11. https://doi.org/10.1002/gps.5646 